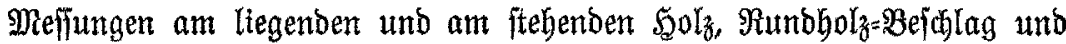

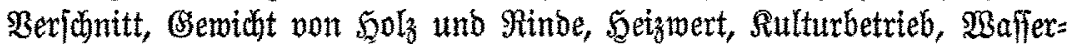

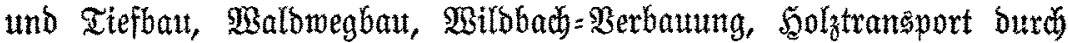

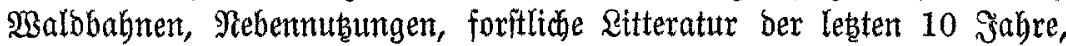

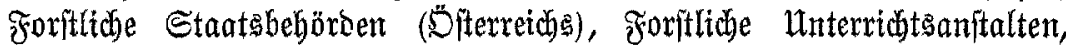
Foritlide Serjudsanitalten, Forituereine.

Der Ralenter, Der mit grofer Sorgfalt bearbeitet if unb beffen

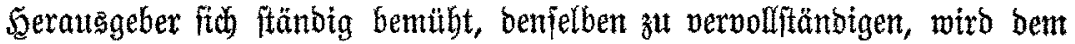
Foritmann, wie aus obiger Snltaltsangabe bervorgeht, nur felten bie Intmort auf eine an ibn berantretende Frage joduldig bleiben unb lann

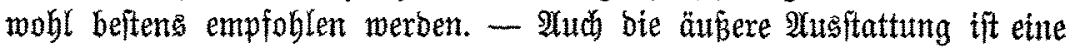
gute und foltbe, wenn aud in threx Erfibeinung - jobroraer Reber-

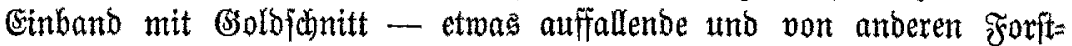
falenbern abweidenbe.

\title{
IV. צtotitizen.
}

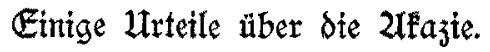

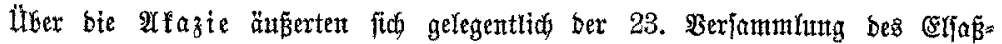
Eotbringifon Forftereits mebrere Rebner in folgenber Wetfe: 1. Sberförfer Bohmant= Rieberbronn: "Bie beretts angebentet, bat ber bolzbänber $\Omega$ aul

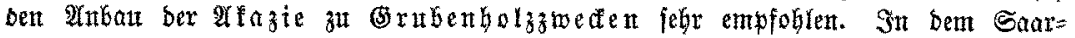

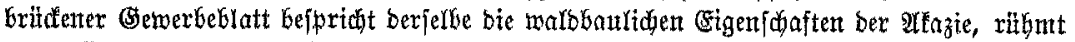

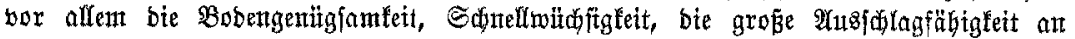

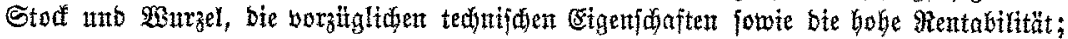
bie Maffen = unb Wertprobuftion betrage bas 2-4 facte von Riefer unb Cidte; bei 15

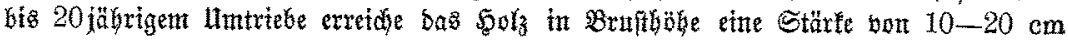
uns ber Ertrag ant Derbholz fteffe fich etwa anf $100 \mathrm{fm}$ pro beftar.

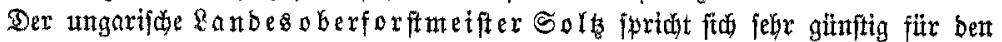

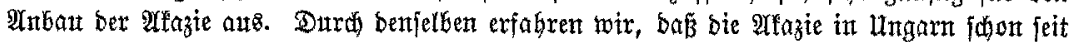

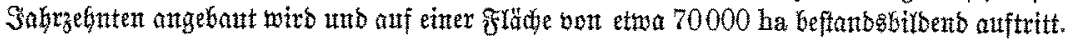

Die Tfazie verlange zum guten Fortlomment gemäbigte firma mo loderen,

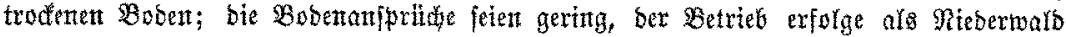

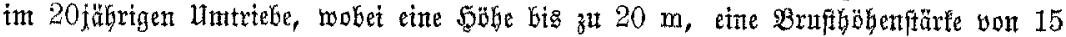

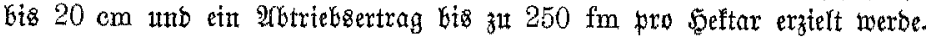

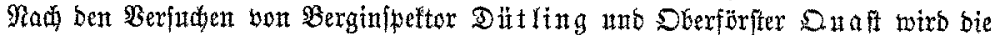

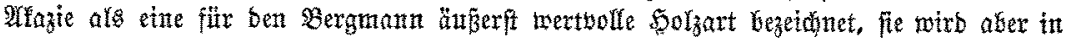

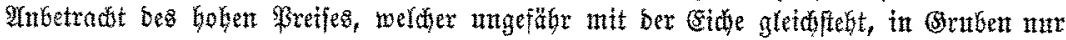

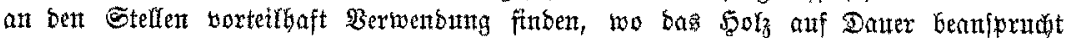

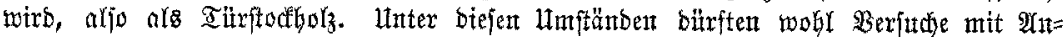

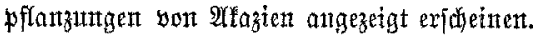

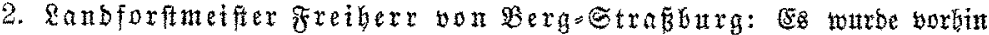

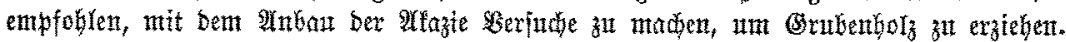

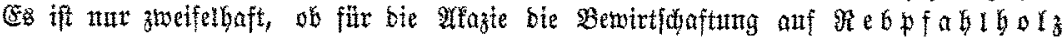




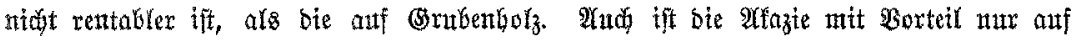
gemiffen Stanborten zu erzighent.

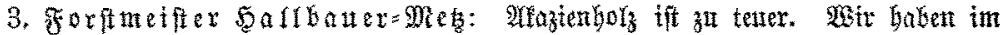

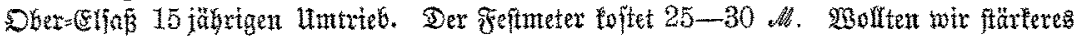

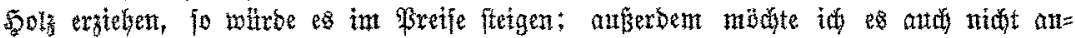

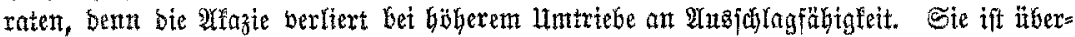

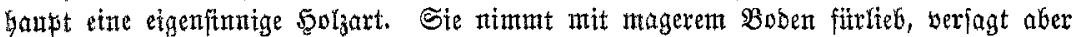

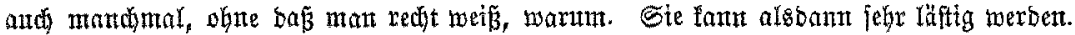

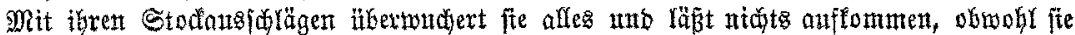

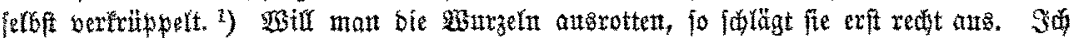

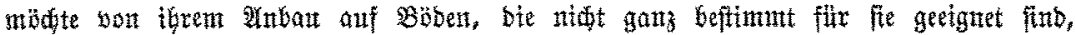
abraten.

E.

\section{Uns Prenterent.}

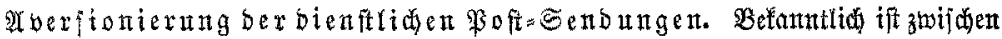

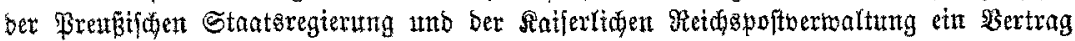

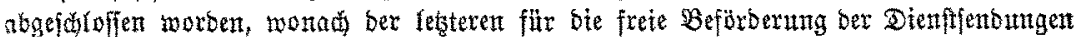

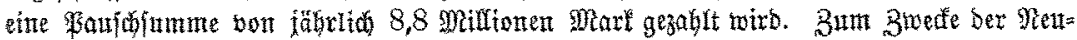

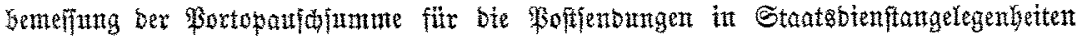

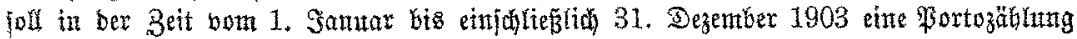

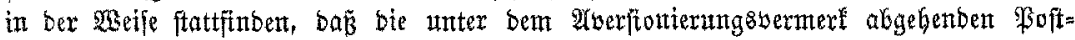

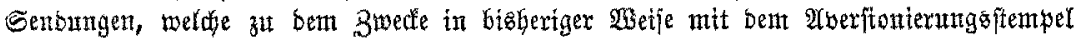

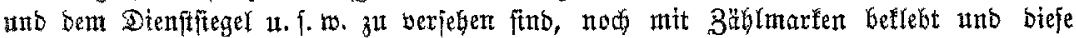

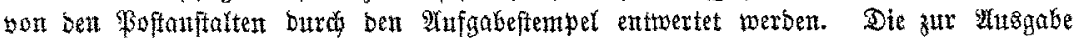
gefungenben Marten, welne za $2,3,5,10,20,25,40$ unb 20 ga augefertigt werben,

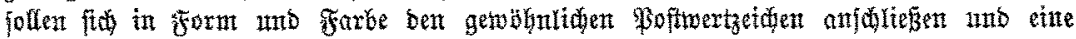

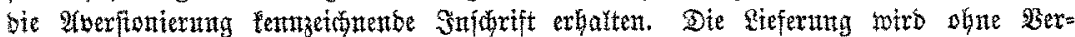

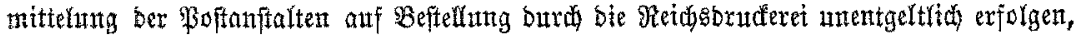

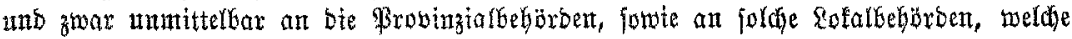
etnen axbebliden Marfentbedarf Gaben.

s.

\section{Waldbrände in Bavern.}

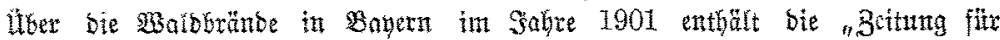

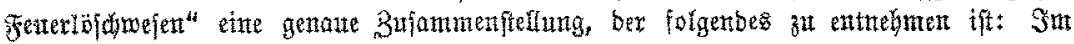

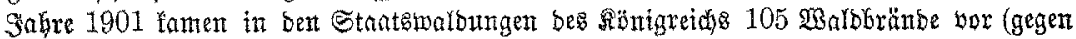

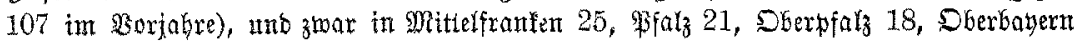
15, Unterfranfen 10, S山waben 7, Sberfrantent 6 tho Nieberbnnert 3 vor. Zerftüt

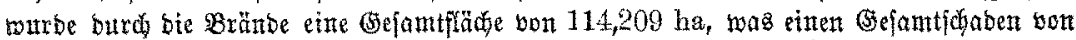

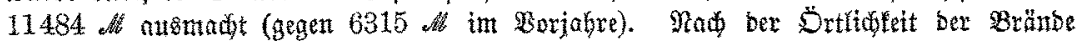

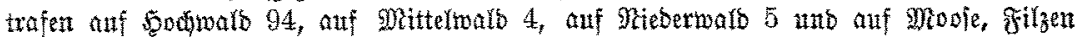

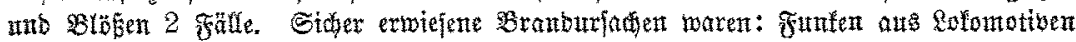

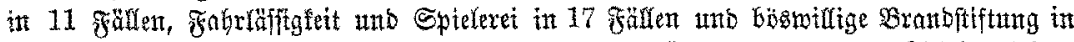

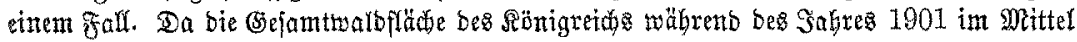
runb 941238 ha betrutg, ettfällt fomit auf 8964 ha @taatßmalb flädse 1 ha Brandflädje.

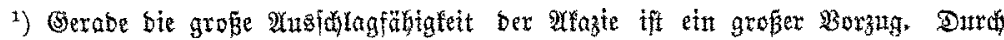

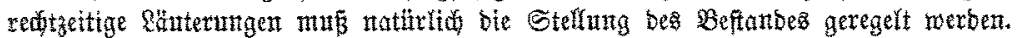

